\title{
Subacute Sclerosing Panencephalitis (SSPE): A Fatal Aftermath of Measles Infection
}

\author{
Marin Thomas Koshy ${ }^{1}$ \\ ${ }^{1}$ M.Sc. Nursing (Medical Surgical Nursing), $2^{\text {nd }}$ Year Student, Rufaida College of Nursing, Jamia Hamdard. \\ DOI: https://doi.org/10.24321/2455.9318.201810
}

\begin{abstract}
Subacute Sclerosing Panencephalitis (SSPE) is a progressive form of encephalitis without a cure. This case report pertains to a primigravida diagnosed with SSPE in her fifth month of pregnancy. She has been married for two years. During her sixth month of pregnancy, she developed signs of SSPE such as behavioral and personality changes, social detachment, reduced involvement in household work which progressed to mutism, altered sensorium, involuntary movement of right half of face and myoclonic jerks involving right upper and lower limbs, in spite of that, she delivered a baby boy who within a month died due to diarrhea. The patient had several episodes of seizures which subsided with antiepileptic and antiviral drugs initially but on March 3, 2018 she again had myoclonic episodes of seizures, from which she did not recover. EEG findings showed periodic episodes of high-amplitude delta-frequency activity associated with the involuntary movements, superimposed on relatively normal background activity and elevated levels of gamma globulin and measles antibody in serum and cerebrospinal fluid was suggestive of SSPE. During pregnancy, marked by physiological immunosuppression, there is a greater chance of SSPE outbreak which requires constant care, follow up and observing initial manifestations of SSPE to delay the course of disease with symptomatic medications or treatment when the inflammatory changes are, possibly, still reversible. The long-term outlook for people with subacute sclerosing panencephalitis (SSPE) is poor. Since the condition is always fatal, the only way to prevent SSPE is to get the measles vaccination.
\end{abstract}

Keywords: Sclerosing, Panencephalitis, Mutism, Seizures, Gammaglobulin

\section{Introduction}

A 27 years old woman, was admitted to the neurology ward of Safdarjung Hospital on March 3, 2018 who was a known case of Subacute Sclerosing Encephalitis on regular treatment presented with complaints of inability to talk, involuntary movement of right half of face and myoclonic movements of right upper and lower limb. She weighed $50 \mathrm{~kg}$ and has been married since 2 years. She was pregnant and was in her $2^{\text {nd }}$ trimester when she presented with signs of SSPE for the first time and the disorder progressed rapidly.

On admission her vital signs were normal, she was conscious but disorientated. Her Glasgow Coma Scale was $\mathrm{E}_{3} \mathrm{~V}_{1} \mathrm{M}_{5}$. The patient was a given tablets Carbamazepine, Clonazepam and Isoprinosine. The condition was well managed by these antiviral and anticonvulsant drugs for a period of 3 months from her previous discharge from neurology ward, further which she had another outbreak of symptoms and kept worsening. EEG findings showed periodic episodes of high-amplitude delta-frequency activity associated with the involuntary movements, superimposed on relatively normal background activity and elevated levels of gammaglobulin and measles antibody in cerebrospinal fluid confirmed SSPE and its severity. Further NCCT head and MRI head suggested progress of clinical course of SSPE to third stage which includes the development of autonomic instability, rigidity, and decreasing levels of consciousness often with decorticate/decerebrate

E-mail Id: marinsusanthomas@gmail.com

Orcid Id: https://orcid.org/0000-0003-2536-062X

How to cite this article: Koshy MT. Subacute Sclerosing Panencephalitis (SSPE): A Fatal Aftermath of Measles Infection. Int J Nurs Midwif Res 2018; 5(1): 46-49. 
posturing in addition to continued cognitive decline as well as myoclonus, seizures, choreoathetosis, apraxia, and visual changes. Her treatment regimen included ryles tube feed, Inj. carbamazepine $200 \mathrm{mg}$ twice daily, Inj. Levera 750mg twice daily, Tab Clonazepam 0.5mg thrice daily, Inj. Valproate $500 \mathrm{mg}$ twice daily and Multivitamin injection $(10 \mathrm{ml})$ once daily intravenously in $500 \mathrm{ml}$ Normal saline. She delivered a baby boy who died within 28days due to diarrhea and history of white discoloration of hand and foot.

\section{Epidemiology}

SSPE is on the decline after the introduction of vaccination in developed countries like United States. ${ }^{1}$ In developing countries like India, SSPE continues to occur presumably due to late introduction of vaccination in 1986 or quality of vaccines used. Serological studies have reported a high annual incidence (21 cases per million population) of SSPE in India. ${ }^{2}$ Molecular and epidemiological studies have shown that outbreaks of measles can occur even in countries that have already implemented vaccination programme due to introduction of variants of measles virus. ${ }^{3}$

\section{Pathophysiology}

Measles first gains access to the body via the upper respiratory tract or the conjunctiva. The virus quickly spreads to the immediate lymph nodes. Destruction of the lymphoid tissues leads to a profound leucopenia. A primary viraemia ensues which is responsible for spreading the virus throughout the rest of the ReticuloEndothelial system and the respiratory system. A secondary viraemia follows whereby the virus is further spread to involve the skin, the viscera, kidney and bladder. The Koplik's spots and the rash in measles are thought to result from a delayed hypersensitivity reaction, the virus antigen being absent from the lesion itself. ${ }^{4}$

In SSPE, the virus is first thought to gain entry to the CNS during the viraemia. SSPE is caused by a persistent CNS infection by the rubeola virus, affecting neurons and glial cells. A large number of nucleocapsids are produced in the neurons and the glial cells. In these cells the viral genes that encode envelope proteins have restricted expression. ${ }^{5}$ As a result, infectious particles like the $M$ protein are not produced, and the virus is able to survive persistently without evoking an immune response. Eventually the infection will lead to SSPE.

\section{Clinical Presentation}

Subacute Sclerosing Panencephalitis (SSPE) generally develops approximately seven to ten years after a person recovers from the measles. The clinical course of SSPE is variable, but affected individuals generally progress through four loosely defined stages. The first stage is characterized primarily by behavioral and personality changes, and may be heralded by a change in school or work performance. The second stage involves continued cognitive decline as well as myoclonus, seizures, choreoathetosis, apraxia, and visual changes. Features of the third stage include the development of autonomic instability, rigidity, and decreasing levels of consciousness often with decorticate/decerebrate posturing. In the final stage, the patient demonstrates quadraparesis, akinetic mutism, active startle responses and coma. The myoclonus and rigidity is usually less prominent at this point. ${ }^{6}$

\section{SSPE and Pregnancy}

SSPE can rapidly progress during pregnancy. It has been suggested that the relative older age of presentation, and unusually rapid neurological deterioration, are partially due to immunological and hormonal alterations of pregnancy. In several reported cases, the disease was associated with the death of the child in utero, or in the immediate peripartum period. ${ }^{7}$

Thiel et al reported a 20-year-old woman who delivered a healthy infant by caesarean section in the 28th gestational week. ${ }^{8}$ Serum analysis of the infant revealed slowly diminishing IgG measles virus antibody titres. After six months, the maternal measles antibodies were no longer detectable in the child's serum.

\section{Diagnostic Evaluation}

\section{Electroencephalography}

Early in the course of the disease, the electroencephalogram (EEG) findings may be normal or show only moderate, nonspecific generalised slowing. The typical EEG pattern is usually seen in myoclonic phase and is virtually diagnostic. The EEG picture is characterised by periodic complexes consisting of bilaterally symmetrical, synchronous, high voltage (200-500 mv) bursts of polyphasic, stereotyped delta waves. Waveforms remain identical in any given lead. These periodic complexes repeat at fairly regular 4-10 second intervals and have 1:1 relationship with myoclonic jerks. $^{9}$

EEG findings in this patient showed periodic episodes of high-amplitude delta-frequency activity associated with the involuntary movements, superimposed on relatively normal background activity and elevated levels of gammaglobulin and measles antibody in cerebrospinal fluid confirmed SSPE and its severity

\section{Cerebrospinal fluid}

In patients with SSPE most of IgG in the cerebrospinal fluid has been shown to be directed against measles virus, 
and the oligoclonal bands can be adsorbed by measles virus. ${ }^{10}$ So raised titres of antimeasles antibodies in the cerebrospinal fluid are diagnostic of SSPE. It is possible to make an accurate diagnosis of SSPE by detecting the measles virus genome in the cerebrospinal fluid.

\section{Neuroimaging}

Neuroimaging has a limited role in the early diagnosis of SSPE. Computed tomography of brain is normal in early stages of disease, in later stages it shows small ventricles and obliteration of hemispheric sulci and interhemispheric fissure due to diffuse cerebral edema. ${ }^{11}$

Magnetic resonance imaging ( $\mathrm{MRI})^{12}$ is more sensitive in detecting white matter abnormalities. Early changes are ill defined high signal intensity areas on T2-weighted images, more commonly seen in the occipital sub cortical white matter than in the frontal region. In most of the cases the grey matter is spared even in advanced clinical and MRI stages. NCCT head and MRI head in this case has suggested progress of clinical course of SSPE to third stage which includes the development of autonomic instability, rigidity, and decreasing levels of consciousness often with decorticate/decerebrate posturing in addition to continued cognitive decline as well as myoclonus, seizures, choreoathetosis, apraxia, and visual changes.

\section{Brain biopsy}

Examination of frozen sections by immunofluorescence technique may demonstrate the presence of measles virus antigens. Reverse transcription polymerase chain reaction can detect various regions of the measles virus RNA in frozen and even paraffin embedded brain tissue specimens of patients with SSPE.

\section{Management}

Unfortunately, there is currently no cure for subacute sclerosing panencephalitis (SSPE). If the the viral progression is diagnosed during stage 1 (even during late stage 1 when stage 2 symptoms start to manifest themselves) then treatment to combat the infection can be administered successfully and chances of survival exist. The treatment for the SSPE infection is the immunomodulator interferon and specific antiviral medications such as ribavirin and inosine pranobex.

For those who have progressed to stage 2 or beyond, the disease is incurable. For patients in the terminal phase of the disease there is a palliative care and treatment scheme this involves anticonvulsant therapy (to help with the bodyss progressive loss of control of the nervous system causing gradually more intensive spasms/convulsions) alongside supportive measures to help maintain vital functioning. ${ }^{13}$
The treatment regimen in this patient included, ryles tube feeding, Inj. carbamazepine 200mg twice daily, Inj. Levera $750 \mathrm{mg}$ twice daily, Tab Clonazepam 0.5mg thrice daily, Inj. Valproate $500 \mathrm{mg}$ twice daily and Multivitamin injection $(10 \mathrm{ml})$ once daily intravenously in $500 \mathrm{ml}$ normal saline.

It is fairly standard as the infection spreads and symptoms intensify that feeding tubes need to be inserted to keep a nutritional balance. As the disease progresses to its most advanced phase, the patient will need constant nursing as normal bodily function declines to the complete collapse of the nervous system.

\section{Conclusion}

SSPE is a slow virus infection caused by aberrant measles virus. This disease is still common in developing and underdeveloped countries. One of the most important limitations in treatment of SSPE is difficulty in recognizing early manifestations of disease to either treat initial inflammatory changes or delay the course of disease with symptomatic medications. The families of patients with SSPE have a lot of physical, psychological, and economical stresses to endure. A great deal of external support is required for these suffering families to cope with these stresses. At present effective measles vaccination seems to be the only solution for this dreaded neurological disorder.

\section{Conflict of interest: None}

\section{References}

1. Hinman AR, Orenstein WA, Bloch AB, Bart KJ, Eddins $D L$, Amler RW,et al. Impact of Measles in the United States. Reviews of Infectious Diseases 1983; 5: 439-444.

2. V. Saha, T. J. John, P. Mukundan, C. Gnanamuthu, S. Prabhakar, G. Arjundas, et al. High Incidence of Sub Acute Sclerosing Panencephalitis in South India. Epidemiology and Infection 1990; 104: 151-156.

3. Kreis S and Shoub BD. Partial Amplification of Measles Nucleocapsid Gene from Stored Sera and Cerebrospinal Fluids for Molecular Epidemiological Studies. Journal of Medical Virology 1998;56: 174-177.

4. Pathogenesis of Measles Virus Infections. Retireved from: virology-online.com/viruses/MEASLES4.htm.

5. Jawetz. Melnick and Adelberg's Medical Microbiology. Lange. 2010: 586. Retrieved from: ISBN 978-0-07174271-9.

6. Santoshkumar B, Radhakrishnan K. Substantial spontaneous long term remissionin subacute sclerosing panencephalitis (SSPE). Department of Neurology. 1998;154(1):83-88.

7. Wirguin I, Steiner I, Kidron D, Brenner T, Udem S, Rager B, et al. Fulminant Subacute Sclerosing Panencephalitis in Association with Pregnancy. Arch Neurol 1988; 45:1324-5.

8. Thiel A, Nau R, Fischer F, Meden H, Harms K, Weissbrich 
B, et al. Healthy Infant delivered by a Mother with Subacute Sclerosing Panencephalitis during pregnancy. Neurology 1996; 46:1604.

9. Kuroiwa $Y$ and Celesia G. Clinical Significance of Periodic EEG patterns. Arch Neurol 1980;37:15-20.

10. Mehta PD, Thormar H, Kulczycki J, Wisniewski HM. Immune Response in Subacute Sclerosing Panencephalitis. Annals of the New York Academy of Sciences 1994; 724:378-84.

11. Modi GH and Campbell BP. Subacute Sclerosing Panencephalitis. Changes on CT scan during Acute
Relapse. Neuroradiology 1989;31:433-434.

12. Tuncay R, Akman-Demir G, Gökyigit A, Eraksoy M, Barlas M, Tolun $\mathrm{R}$, et al. MRI in Subacute Sclerosing Panencephalitis. Neuroradiology 1996; 38: 636-640.

13. NINDS Subacute Sclerosing Panencephalitis Information Page. National Institute of Neurological Disorders and Stroke. February 2016. Retrieved from: https:// www.ninds.nih.gov/Disorders/All-Disorders/SubacuteSclerosing-Panencephalitis-Information-Page.

Date of Submission: 2018-04-05 Date of Acceptance: 2018-04-30 